\title{
Organize Suç ve Terör Örgütleri ile Mücadelede Önleyici İstihbarat Hizmeti için Matematiksel Yaklaşım
}

\author{
Murat BEŞER \\ İstanbul Üniversitesi İktisat Fakültesi, İktisat Bölümü, İstanbul
}

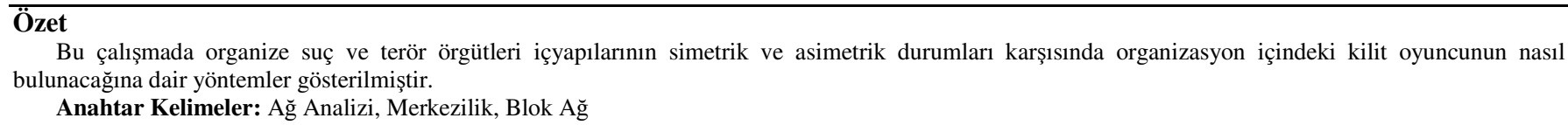

\section{A Mathematical Approach to the Preventive Intelligence Service Designed for the Encounter with the Organized Criminal and Terror Enterprise}

\author{
Abstarct \\ In this work methods how to find the key player in the organization are illustrated in case of symetrical and asymetrical circumtances of the inner structure \\ of the organized criminal and terror enterprise. \\ Keywords: Network Analysis, Centrality, Block Network
}

\section{Giriş}

Organize suç ve terör örgütleri ile mücadele, zaman yönünden uzun maddi yön açısından oldukça pahalı bir çaba gerektirmektedir. Kaynakların kisitlı olması, bu tip organizasyonlar hakkındaki istihbarat faaliyetlerinin daha etkin ne şekilde yapılabilir sorununu sürekli gündemde tutmaktadır. Bu konuda ki yaklaşımlardan biri matematiksel yöntemlerin organize suç ve terör örgütleri yapısının analizinde kullanılması olarak karşımıza çıkmaktadır. Genel olarak organize suç ve terör örgütlerinin hiyerarşik yapısının statikliği, örgüt yapılarının matematiksel ağ teorisine indirgenerek analizinin yapılmasına olanak sağlamaktadır. Buna göre organizasyon içinde her bir kişi veya grup bir nokta ve bu noktalar arasında tanımlı iletişim ise bu noktaları birleştiren doğru parçası ile ifade edilmekte böylelikle matematiksel olarak tek boyutlu simpleksel kompleks olarak adlandırdığımız organizasyon iskeleti / ağı (network) ortaya çıkmaktadır. Burada temel sorun ilgili organizasyon ağı içindeki noktaların pozisyonunun ve ağırlığının ne derece önemli olduğunun hesaplanmasıdır. Bu yaklaşım sayesinde organizasyon içinde ki bilgi akışına hakim ve organizasyon içindeki diğer kişilere ulaşabilirlik konusunda en aktif üye(ler) bulunmuş olacak ve kısıtlı kaynakların organizasyon hakkında bilgi edinmek için en etkin şekilde nasıl kullanılacağı sorusuna kısmi olarak cevap elde edilecektir.

Merkezilik konusunda yapılan analizler 2. Dünya savaşının öncesinden günümüze kadar aktif bir alan olarak ortadadır ve bu konuda şimdiye kadar çeşitlik ölçüler geliştirilmiştir. Bunlara örnek olarak: Derece, Aralık, Yakınlık ve Bonacich Öz Vektör yöntemleri ön plana çıkmaktadır. Bu metotlardan Bonacih Öz Vektör yöntemi bazı eksiklikleri olsa da organizasyon yapılarında merkezi / anahtar noktanın bulunmasında oldukça kullanışlıdır.
$\mathrm{Bu}$ çalışmanın ilk bölümünde matematiksel graf teorisi hakkında bilgi verilecek ikinci bölümde Derece, Aralık, Yakınlık ve Bonacich Öz Vektör yöntemlerinin tanımları yapılarak 11 Eylül 2001 yılında ABD'de gerçekleştirilen terör saldırısına karışan 19 El-Kaide terör örgütü üyesinin oluşturduğu ăg yapısında kilit üyenin bulunmasında kullanılacaktır. Üçüncü bölümde ise ağ yapılarında noktalar ve noktalar arasındaki bağlara sayısal ağırlık verildiğinde kilit oyuncunun bulunması blok yapılı ağlar ve ve bunlar içinde tam alt-ağ şeklinde tanımlanmış iç hücreler durumu göz önünde bulundurularak tanımlanacaktır.

\section{A $\breve{g}$ Teorisine Ait Bazı Kavramlar}

A $\breve{g}$ yapıları, $N=\{1, \cdots, n\}$ sinırlı sayıda nokta ve bu noktalar arasında tanımlı tüm doğrusal bağların bir alt kümesi olan $E \subset N \times N$ den meydana gelmektedir. Bu ağ yapılarına ait $G=(N, E)$ siralı ikilisi 1-simpleksel kompleks, graf olarak da tanımlanır. için $h_{i} h_{j}=\left\{\begin{array}{l}1: h_{i} h_{j}=h_{j} h_{i} \in E \\ 0: h_{i} h_{j}=h_{j} h_{i} \notin E\end{array} \quad\right.$ ifadesi iki noktanın birbiri ile doğrudan bağlantılı olduğunu ifade etmektedir. $e \in N$ noktasının komşuluğu $\mathrm{N}(e)=\{f \in N \mid$ ef $\in E$, ef $=1\}$ kümesidir. A ̆g yapısı içindeki tüm noktalar birbirleri ile bağlantılı ise tam ağ olarak tanımlanır. $\tilde{N} \subset N$ alt kümesi için $G_{\tilde{N}}=\left(\tilde{N}, E_{\tilde{N}}\right)$ ifadesi bir alt ağ yapısı oluşturmaktadır.

Ağ üzerinde bir $e \in N$ noktasından başlayan hareket tekrar $e \in N$ noktasında son buluyorsa, devir olarak adlandırılır. İçinde devir bulundurmayan bağlantılı ağlar, ağaç olarak adlandirılır. 


\section{Ağlarda Merkezilik}

Matematiksel olarak merkezilik, $G=(N, E)$ ağ yapısının noktalarından $\square$ görüntü kümesine giden fonksiyondur. Diğer bir ifade ile $\square^{N}$ vektör uzayına ait bir vektördür. Tanım kümesinin tam sıralı olması özelliğinden hareketle, merkezilik vektörünün her bileşeni birbirleri ile mukayese edilebilmekte böylece ilgili ağa ait noktalar arasında önem sıralaması oluşturulabilmektedir. Literatürde belli varsayımlar altında çeşitli merkezilik fonksiyonları tanımlanmıştır. Bunlardan bazıları:

1. Derece Merkeziliği

2. Yakınlık Merkeziliği

3. Aralık Merkeziliği

4. Bonacich Özvektör Merkeziliği

\section{I.a Derecenin Merkeziliği}

$e \in N$ noktasının doğrudan bağlantılı olduğu noktaların sayısıdır. Suç örgütleri tabanlı incelendiğinde, organizasyonun $e$ üyesi organizasyon içinde kaç oyuncu ile doğrudan bağlantılı olduğunu göstermektedir. $G=(N, E)$ ağ yapısı ve $k \in N$ oyuncusu için $C_{d}(k ; G=(N, E))$ normalleştirilmiş derece merkeziliği $C_{d}(k ; G=(N, E))=\frac{\left|N_{k}(G=(N, E))\right|}{n-1}$ formülü ile hesaplanır.

\section{I.b Yakınlığın Merkeziliği}

$e \in N$ noktasının her $a \in N \quad\{e\}$ noktasına ulaşmak için gerekli en kısa yolun toplamıdır. $\mathrm{Bu}$ ifade suç organizasyonlarında $e$ üyenin, organizasyon içindeki keyfi bir üyeye bağlantıları yardımı ile ulaşabilme kabiliyetini göstermektedir. $G=(N, E)$ ağ yapısı ve $k \in N$ oyuncusu için $C_{y}(k ; G=(N, E))=\frac{n-1}{\sum_{j \neq k} d(k, j ; G=(N, E))}$ şeklinde gösterilir.

\section{I.c Aralığın Merkeziliği}

$e \in N$ noktasının diğer iki noktanın bağlanmasında oynadığı rol ile ölçülür. Buna göre $a, b \in N \quad\{e\}$ noktaları için $e$ noktasından geçen ve diğer iki noktayı birleştiren en kısa yoldur. $\mathrm{Bu}$ ifade suç organizasyonlarında $e$ üyenin diğer üyeler arası iletişimde ne oranda belirleyici olduğunu ifade etmektedir. $G=(N, E)$ ağ yapısı ve $k \in N$ oyuncusu için

$$
C_{a}(k ; G=(N, E))=\frac{2}{(|N|-1)(|N|-2)} \sum_{\substack{j, i \in N \\ j<i}} \frac{s_{j k i}}{S_{k i}}
$$

şeklinde tanımlanır. Bu denklemde $s_{j k i}$ ifadesi uç noktaları $j, i \in N$ olan ve $k$ noktasından geçen en kısa yolun sayısı, $s_{k i}$ ise $j, i \in N$ noktalarını birleştiren en kısa yol sayısıdır.

\section{I.d Bonacich Özvektör Merkeziliği}

Bonacich özvektör merkeziliğini diğer merkezilikten ayıran özellik, $e \in N$ noktasının değerini, bu noktanın komşuluk değerleri tarafından meydana getirilmesidir. Bu ifade organizasyonlarda $e$ üyesinin irtibatlı olduğu önemli üyeler sayesinde belli bir önem derecesine sahip anlamına gelmektedir. Bu yüzden ilgili oyuncunun merkezilik derecesi salt kendine bağlı değil, irtibatlı olduğu üyelere bağlı olarak ölçülür. $\quad a, b \in \square_{++} \quad$ ve $b$ oldukça küçük değer için $C_{b o}(a, b ; G=(N, E))=(I-b G)^{-1} a G \overline{1}$ ile hesaplanır.

Burada $G, I$ ve $\overline{1}$ matrisleri sırası ile ağ matrisi, birim matris ve tüm elemanları 1 olan vektördür.

Aşağıda verilen ağ yapısı ABD'de 11 Eylül 2001 yılında gerçekleştirilen terör saldırısının failleri olan 19 El-Kaide terör örgütü mensubunun ilişki bağını göstermektedir. (Krebs, http://journals.uic.edu, 2002)

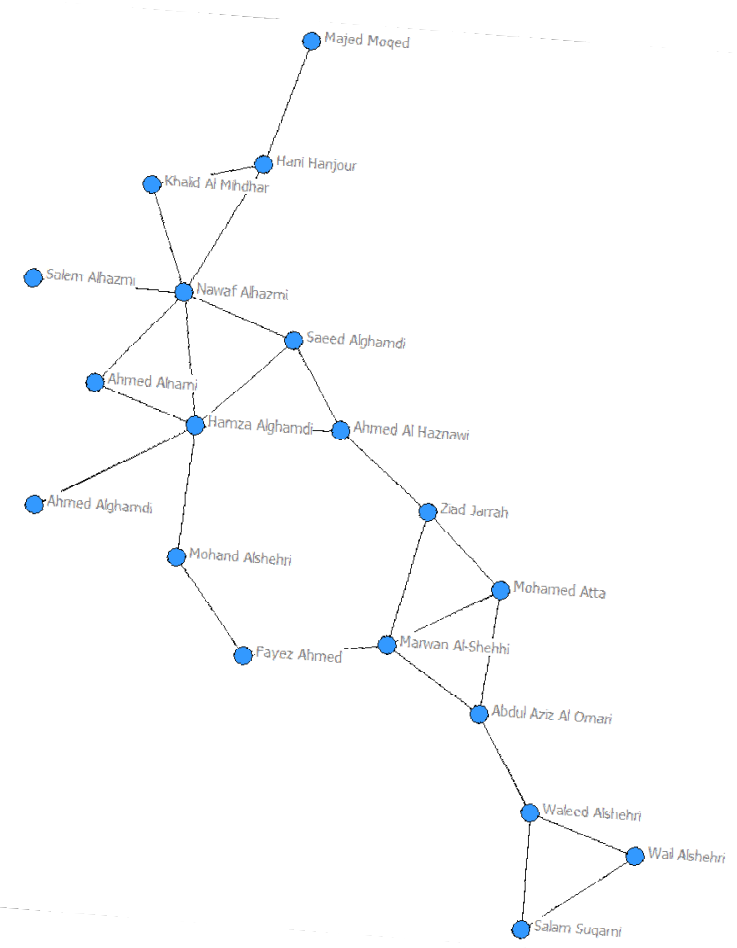

Şekil 1.

Şekil 1'de gösterilen ă̆ yapısı incelendiğinde ilgili ElKaide terör örgütü üyelerinin birbirleri ile doğrudan iletişime geçmelerinin kısıtlı olduğu, Hani Hanjour, Nawaf Alhazmi, Abdul Aziz Al Oman ve Waleed Alshehri'nin iletişim ağ içinde ağ yapısının bağlantılı kalmasında kritik üyeler olduğu ortaya çıkmaktadır. Tablo 119 El-Kaide terör örgütü mensubunun ait olduğu ilişki ağı için merkezilik analizlerinin önem sırasına göre sonuçlarını göstermektedir. 
Tablo 1.

\begin{tabular}{|c|c|c|c|c|}
\hline & Derece & Yakınlık & Aralık & Bonacich \\
\hline 1 & $\begin{array}{l}\text { Nawaf } \\
\text { Alhazmi* }\end{array}$ & $\begin{array}{l}\text { Hamza } \\
\text { Alghamdi }\end{array}$ & $\begin{array}{l}\text { Hamza } \\
\text { Alghamdi }\end{array}$ & $\begin{array}{l}\text { Nawaf } \\
\text { Alhazmi* }\end{array}$ \\
\hline 2 & $\begin{array}{l}\text { Hamza } \\
\text { Alghamdi* }\end{array}$ & $\begin{array}{l}\text { Ahmed Al } \\
\text { Haznawi }\end{array}$ & $\begin{array}{l}\text { Nawaf } \\
\text { Alhazmi }\end{array}$ & $\begin{array}{l}\text { Hamza } \\
\text { Alghamdi* }\end{array}$ \\
\hline 3 & $\begin{array}{l}\text { Marwan Al- } \\
\text { Shehhi }\end{array}$ & $\begin{array}{l}\text { Saeed } \\
\text { Alghamdi } \\
*\end{array}$ & $\begin{array}{l}\text { Ahmed Al } \\
\text { Haznawi }\end{array}$ & $\begin{array}{l}\text { Marwan Al- } \\
\text { Shehhi }\end{array}$ \\
\hline 4 & $\begin{array}{l}\text { Hani } \\
\text { Hanjour* }\end{array}$ & $\begin{array}{l}\text { Mohand } \\
\text { Alshehri* }\end{array}$ & Ziad Jarrah & $\begin{array}{l}\text { Waleed } \\
\text { Alshehri* }\end{array}$ \\
\hline 5 & $\begin{array}{l}\text { Mohamed } \\
\text { Atta* }\end{array}$ & $\begin{array}{l}\text { Ziad } \\
\text { Jarrah }\end{array}$ & $\begin{array}{l}\text { Abdul Aziz } \\
\text { Al Omari }\end{array}$ & $\begin{array}{l}\text { Abdul Aziz } \\
\text { Al Omari* }\end{array}$ \\
\hline 6 & Ziad Jarrah* & $\begin{array}{l}\text { Fayez } \\
\text { Ahmed* }\end{array}$ & $\begin{array}{l}\text { Marwan Al- } \\
\text { Shehhi }\end{array}$ & $\begin{array}{l}\text { Mohamed } \\
\text { Atta* }\end{array}$ \\
\hline 7 & $\begin{array}{l}\text { Saeed } \\
\text { Alghamdi* }\end{array}$ & $\begin{array}{l}\text { Nawaf } \\
\text { Alhazmi* }\end{array}$ & $\begin{array}{l}\text { Waleed } \\
\text { Alshehri }\end{array}$ & Ziad Jarrah* \\
\hline 8 & $\begin{array}{l}\text { Abdul Aziz } \\
\text { Al Omari* }\end{array}$ & $\begin{array}{l}\text { Marwan } \\
\text { Al-Shehhi }\end{array}$ & $\begin{array}{l}\text { Mohand } \\
\text { Alshehri }\end{array}$ & $\begin{array}{l}\text { Ahmed Al } \\
\text { Haznawi* }\end{array}$ \\
\hline 9 & $\begin{array}{l}\text { Ahmed Al } \\
\text { Haznawi* }\end{array}$ & $\begin{array}{l}\text { Mohamed } \\
\text { Atta* }^{*}\end{array}$ & $\begin{array}{l}\text { Mohamed } \\
\text { Atta* }\end{array}$ & $\begin{array}{l}\text { Saeed } \\
\text { Alghamdi* }\end{array}$ \\
\hline 10 & $\begin{array}{l}\text { Waleed } \\
\text { Alshehri* }\end{array}$ & $\begin{array}{l}\text { Ahmed } \\
\text { Alnami* }\end{array}$ & $\begin{array}{l}\text { Fayez } \\
\text { Ahmed* }\end{array}$ & $\begin{array}{l}\text { Hani } \\
\text { Hanjour* }\end{array}$ \\
\hline 11 & $\begin{array}{l}\text { Wail } \\
\text { Alshehri** }\end{array}$ & $\begin{array}{l}\text { Ahmed } \\
\text { Alghamdi }\end{array}$ & $\begin{array}{l}\text { Saeed } \\
\text { Alghamdii* }\end{array}$ & $\begin{array}{l}\text { Salam } \\
\text { Suqami* }\end{array}$ \\
\hline 12 & $\begin{array}{l}\text { Ahmed } \\
\text { Alnami** }\end{array}$ & $\begin{array}{l}\text { Abdul } \\
\text { Aziz Al } \\
\text { Omari }\end{array}$ & $\begin{array}{l}\text { Hani } \\
\text { Hanjour* }\end{array}$ & $\begin{array}{l}\text { Wail } \\
\text { Alshehri* }\end{array}$ \\
\hline 13 & $\begin{array}{l}\text { Fayez } \\
\text { Ahmed** }\end{array}$ & $\begin{array}{l}\text { Hani } \\
\text { Hanjour* }\end{array}$ & $\begin{array}{l}\text { Salam } \\
\text { Suqami }\end{array}$ & $\begin{array}{l}\text { Fayez } \\
\text { Ahmed }\end{array}$ \\
\hline 14 & $\begin{array}{l}\text { Khalid Al } \\
\text { Mihdhar** }\end{array}$ & $\begin{array}{l}\text { Khalid Al } \\
\text { Mihdhar* }\end{array}$ & $\begin{array}{l}\text { Ahmed } \\
\text { Alnami }\end{array}$ & $\begin{array}{l}\text { Mohand } \\
\text { Alshehri }\end{array}$ \\
\hline 15 & $\begin{array}{l}\text { Mohand } \\
\text { Alshehri** }\end{array}$ & $\begin{array}{l}\text { Salem } \\
\text { Alhazmi }\end{array}$ & $\begin{array}{l}\text { Wail } \\
\text { Alshehri }\end{array}$ & $\begin{array}{l}\text { Ahmed } \\
\text { Alnami }\end{array}$ \\
\hline 16 & $\begin{array}{l}\text { Salam } \\
\text { Suqami** }\end{array}$ & $\begin{array}{l}\text { Waleed } \\
\text { Alshehri }\end{array}$ & $\begin{array}{l}\text { Khalid Al } \\
\text { Mihdhar }\end{array}$ & $\begin{array}{l}\text { Khalid Al } \\
\text { Mihdhar }\end{array}$ \\
\hline 17 & $\begin{array}{l}\text { Salem } \\
\text { Alhazmi* }\end{array}$ & $\begin{array}{l}\text { Majed } \\
\text { Moqed }\end{array}$ & $\begin{array}{l}\text { Ahmed } \\
\text { Alghamdi }\end{array}$ & $\begin{array}{l}\text { Ahmed } \\
\text { Alghamdi }\end{array}$ \\
\hline 18 & $\begin{array}{l}\text { Ahmed } \\
\text { Alghamdi* }\end{array}$ & $\begin{array}{l}\text { Salam } \\
\text { Suqami* }\end{array}$ & $\begin{array}{l}\text { Salem } \\
\text { Alhazmi }\end{array}$ & $\begin{array}{l}\text { Salem } \\
\text { Alhazmi* }\end{array}$ \\
\hline 19 & $\begin{array}{l}\text { Majed } \\
\text { Moqed* }\end{array}$ & $\begin{array}{l}\text { Wail } \\
\text { Alshehri* }\end{array}$ & $\begin{array}{l}\text { Majed } \\
\text { Moqed }\end{array}$ & $\begin{array}{l}\text { Majed } \\
\text { Moqed* }\end{array}$ \\
\hline
\end{tabular}

Her sütunda tanımlı yıldız *, ** işaretlerine sahip art arda gelen isimler aynı önem derecesine sahiptir.

Tablo 1'den sırası ile Hamza Alghamdi ve Nawaf Alhazmi'nin ilgili ağ yapısına göre kilit üyeler olduğu açıkça görülmektedir. Majed Moqed, Salam Suqami ve Ahmed Alghamdi'nin ağ yapısında kilit üye olmaya en uzak kişiler olduğu açıktır.

\section{A $\breve{g}$ Yapılarına Alternatif Yaklaşım}

Önceki bölümde organizasyon içindeki üyelerin önem dereceleri/ağırlıkları eşit olduğu varsayımından hareket edilmiş ve merkezilik analizleri yardımı ile bu organizasyonlar içinde kilit kişilerin nasıl bulunacağı gösterilmiştir. Ancak gerek terör gerek organize suç örgütlerinde mevcut olan hiyerarşik yapı, üyeler arasında ki niteliksel farklılık (silah uzmanlığı, propaganda yeteneği, deneyim), üyelerin konumları arasında asimetrik bir yapı oluşmasını doğurmaktadır.
Terör ve suç organizasyonları içinden gerek istihbarat toplama, gerek yönlendirme çalışması yapılırken benzer asimetrik durumlar ortaya çıkmaktadır. Organizasyon içinde bu işlemleri gerçekleştirecek kişinin diğer üyeler ile olan ilişkisinin yoğunluğu yanı sıra bilgi edindiği kişilerinde güvenilirliği karşı karşıya kalınan esas kısıtları oluşturmaktadır. Bu alt bölümde suç ağı yapısına bu iki kriterin eklenmesi ile organizasyon içinde daha önceden belirlenmiş içyapılardan en etkin şekilde bilgi elde edebilecek üyenin nasıl bulunacağı blok ağ yapısına sahip durumlar için gösterilmektedir.

\section{III.a Ağırlık Eklentili A $\breve{g}$ Yapısı}

$\mu: E \rightarrow(0,1]$ fonksiyonu, veri ağ yapısında iki kişi arasındaki ilişkinin yoğunluğunu gösteren fonksiyon için $h_{i, i+1} \in E$ bağlantısının $\mu\left(h_{i, i+1}\right)$ değeri sıfıra yaklaştıkça ilişkinin yoğunluğunun düşük, 1 'e yaklaştıkça yoğunluğunun daha fazla olduğunu, $\lambda: N \rightarrow(0,1]$ fonksiyonu ise veri ağ yapısında $i \in N$ bireyin verdiği bilgiye güven oranını ifade eden ağırlık için $\lambda(i)$ değeri 1 'e yaklaştıkça verdiği bilgilerdeki hata payının düştüğünü göstermektedir. $G=(N, E, \lambda, \mu)$, yukarıda tanımlanan ağırlık fonksiyonları eklentili ăg yapısını ifade etmektedir. $\mathrm{P}=\left(\mathrm{P}_{i}: 1 \leq i \leq k\right)$ alt-ağ kümesi veri ağ yapısında iç hücre ya da iç grup olarak tanımlanabilir. Örneğin $\mathrm{P}_{i}$ iç hücresinde $e_{1}^{i} \in \mathrm{P}_{i}$ noktası ile iletişime geçildiğinde bu noktadan itibaren $\mathrm{P}_{i}$ içindeki diğer tüm noktalar ile iletişime geçilme zorunluluğu geçerli olsun (Puerto vd., 2008: 2891). $\tilde{\lambda}: \mathrm{P} \rightarrow(0,1]$ dönüşümü her alt-ağa güven değeri atamaktadır. $e, h \in E$ için $S(e, h)$ iki nokta arasındaki en kısa yolu, $d(e, h)$ bu yolun uzunluğunu göstermektedir. $e \in E$ noktası ile $\mathrm{P}_{i}$ alt-ağ arasında ki en kısa yolun uzunluğu $d\left(e, \mathrm{P}_{i}\right)=\min _{e_{j}^{i} \in \mathrm{P}_{i}} d\left(e, e_{j}^{i}\right) \quad$ şeklinde tanımlanır.

$$
G=(N, E, \lambda, \mu) \text { bağlantılı ağ yapısında bir } e \in E
$$

noktası çıkarıldığında bağlantılılık özelliğini kaybediyorsa bu noktaya kesim noktası denir. Maksimum bağlantılı ve kesim noktası içermeyen alt-ağlar blok olarak adlandırılır. Tanım gereği iki blok en fazla tek ortak noktaya sahiptir. Her alt-ağ yapısındaki nokta kendi ait oldukları alt-ağda ki noktalar ile doğrudan bağlantılı ise bu alt-ağa tam yapılı denir. Alt-ağları tam yapılı blok olan ağlara blok-ağ olarak adlandırılır. Ağaç yapılarının özel tip blok-ağ olduğu açıktır, zira uç noktalar dışındaki her nokta bir kesim noktası olmaktadır ve $K_{2}$ ile göstereceğimiz $e \in E$ bağlantılarının birleşiminden meydana gelmektedir. $K_{n: n \geq 3}$ notasyonu ise $n$ noktalı tam ağ yapısını ifade etmektedir. Şekil 3 ağ yapısı ele alınırsa $K_{3}=\{9,29,30\},\{20,21,22\},\{9,27,28\}$,

$K_{4}=\{14,15,16,17\}, \quad K_{5}=\{6,7,8,9,10\}, \quad K_{2} \quad$ lerden meydana gelen ağaç yapıları ise $\{23,24,25,26,27\}$, $\{10,11,12,13,18,19,20\}, \quad\{1,2,3,4,5,6$,$\} den meydana$ gelmektedir. 


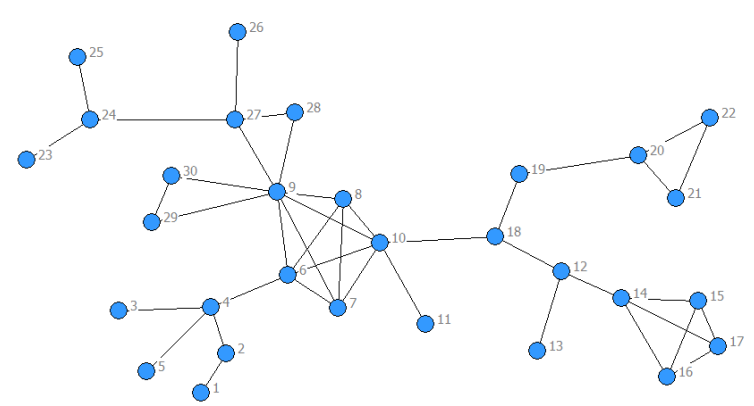

Şekil 2

Yukarıda ki ağ yapısı içinde iç hücre yapıları $K_{2}{ }^{\prime}$ ler tarafından meydana gelen ağaçlar için keyfi bağlantılı alt ağaç, $K_{n: n \geq 3}$ için tam yapılı alt ağ olacaktır. Örneğin $\{10,11,12,13,18,19,20\} \quad$ için $\{10,11,12,18,19,20\} \quad$ alt ağacı, $K_{5}=\{6,7,8,9,10\}$ için $K_{3}=\{8,9,10\}$ alt-ağı birer alt hücre yapısı meydana getirirler. Yukarıdaki bilgilerden hareketle ağ içinde bilgi akışına en kısa sürede hakim olacak kişi aşağıdaki optimizasyon yöntemi ile elde edilir.

$$
\min _{x \in N} f(x)=\sum_{i=1}^{k} \lambda(i) d\left(\begin{array}{ll}
\mathrm{P}_{i} &
\end{array}\right)
$$

Blok-ağ yapılarında (1) nolu özelliği sağlayacak noktanın araştırılmasında en verimli yollardan biri ă yapısından ağaç tipinde yeni bir ağ yapısı elde etmek olacaktır. Bu yeni ağın noktalar kümesi, ana ağ yapısının blokları ve bloklar arasında tanımlı noktalardır. Diğer bir değişle, her $K_{n: n \geq 3}$ yapılı blok ve $K_{2}$ 'lerin birleşimlerinden meydana gelmiş ağaçlar bu yeni ağ sisteminde nokta ile ifade edilmektedir. Aşağıda verilen ağaç tipi Şekil 3'de tanımlı ağ yapısından elde edilmiş yeni ağdır. (Burkard ve Krarup, 1998: 199-200) Bu yeni ağı $\Omega=\left(N_{\Omega}, E_{\Omega}\right)$ ile gösterelim.

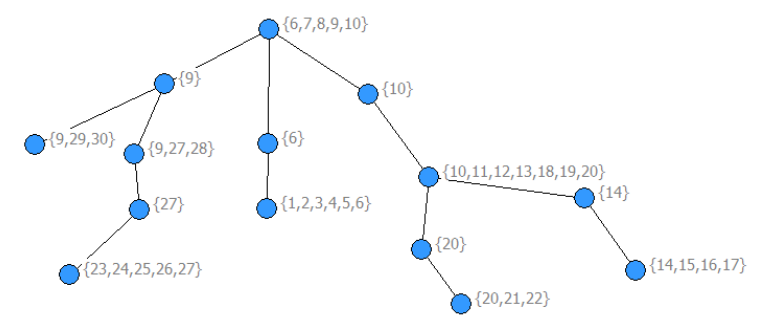

Şekil 3

$$
\text { Ön }\left(a_{i}\right)=\left\{a_{j}: a_{j} a_{i} \in E_{\Omega}\right\}
$$

$\operatorname{Son}\left(a_{i}\right)=\left\{a_{j}: a_{i} a_{j} \in E_{\Omega}\right\}$ kümeleri $a_{i} \in N_{\Omega}$ ile doğrudan bağlantılı sırası ile önce ve sonra gelen noktalar kümesidir. $a_{i} \in N_{\Omega}$ için $\Omega_{a_{i}}, \Omega=\left(N_{\Omega}, E_{\Omega}\right)$ ağacı içinde başlangıç noktası $a_{i}$ olan maksimum alt-ağaç yapısıdır. Bu alt ağaç yapısının ana-ağ yapısındaki görüntüsü $N\left[\Omega_{a_{i}}\right]$ şeklinde gösterilir.

Çalışmanın bu noktasından sonra ilk olarak ana-ăg yapısının $K_{2}$ 'lerin birleşimlerinden meydana gelmiş ağaçlar ve $K_{n: n \geq 3}$ yapılı bloklara sinırlandırıldığı durumlarda yerel optimizasyon problemine dair çözüm yöntemleri gösterilecektir. Daha sonra genel optimizasyon analizi ana-ağ yapısından elde edilmiş ağaç yardımı ile elde edilecektir.

\section{III.b Ağaç Yapıları Üzerinde Optimizasyon}

$G=(N, E, \lambda, \mu)$ ağaç yapısı ve bu yapı içinde $\mathrm{P}=\left(\mathrm{P}_{i}: 1 \leq i \leq k\right)$ iç hücre tanımlansın. $r \in N$ başlangıç noktası için $x \neq r, y, z \in N, \quad x y \in E, \quad$ Ön $(x)=y \quad$ ve $z \in G_{x}$ kabul edilsin. $d\left(r, e_{j}^{i}\right)_{e_{j}^{i} \in \mathrm{P}_{i}}$ noktası $\mathrm{P}_{i}$ 'in başlangıç noktası kabul edilir. $\lambda(i)$ ve $\tilde{\lambda}\left(\mathrm{P}_{i}\right)$ sırası ile nokta ve iç hücre ağırlıklarını ifade eder. Aşağıda verilecek olan işlem süreci, ağaç yapıları üzerinde optimal noktanın bulunmasında kullanılmaktadır. (Zhang vd., 2010: 102; Cheng vd., 2010: 1041)

$$
\begin{aligned}
& \tilde{\lambda}(x)=\left\{\begin{array}{l}
\lambda(x)+\lambda\left(\mathrm{P}_{i}\right): \text { x noktasi } \mathrm{P}_{i}{ }_{i} \text { nın kökü ise } \\
\lambda(x)
\end{array}\right. \\
& \tilde{\lambda}_{L}(x)=\sum_{\mathrm{P}_{i} \subseteq G_{x}} \lambda\left(\mathrm{P}_{i}\right)+\sum_{v \in V\left(G_{x}\right)} \lambda(x) \\
& \Gamma_{G}=\sum_{\mathrm{P}_{i} \subseteq G} \lambda\left(\mathrm{P}_{i}\right)+\sum_{v \in V(G)} \lambda(x) \\
& \tilde{\lambda}(x y)=\left\{\begin{array}{l}
\lambda\left(\mathrm{P}_{i}\right): x y \in E\left(\mathrm{P}_{i}\right) \\
0
\end{array}\right. \\
& f_{G}(x)=\sum_{\mathrm{P} i \subseteq G} \lambda\left(\mathrm{P}_{i}\right) d\left(\mathrm{P}_{i}, x\right)+\sum_{v \in V(G)} \lambda(x) d(v, x) \\
& f_{G}(z)=\min _{v \in V\left(G_{x}\right)} f_{G}(v) \\
& \Delta_{G}(x, y)=f_{G}(y)-f_{G}(x) \\
& \Delta_{G}^{*}(x)=f_{G}(y)-\min _{v \in V\left(G_{x}\right)} f_{G}(v)=f_{G}(y)-f_{G}(z)(9) \\
& \varphi_{G}(x)=\sum_{\mathrm{P} i \subseteq G_{x}} \lambda\left(\mathrm{P}_{i}\right) d\left(\mathrm{P}_{i}, y\right)+\sum_{v \in V\left(G_{x}\right)} \lambda(v) d(v, y)
\end{aligned}
$$

$G=(N, E, \lambda, \mu)$ ağaç yapısına ait her $t \in V(G)$ noktası için yukarıda tanımlı sonuçlar elde edilir. (9) numaralı denklem yerel optimal değeri sağlayan noktayı gösterir. $\tilde{t} \in V(G)$ değeri ilgili ağaç için esas başlangıç noktası için,

$$
f_{G}^{*}=\varphi_{G}(\tilde{t})-\Delta_{G}^{*}(\tilde{t})
$$

sonucu $t \in V(G)$ noktalarına sayısal değeri atamaktadır, bu sayede ilgili noktalar sayısal olarak birbirleri ile mukayese edilerek optimum nokta bulunabilmektedir.

\section{III.c $K_{n: n \geq 3}$ Yapıları Üzerinde Optimizasyon}

$K_{n: n \geq 3}$ tam yapılı ağ ve bunun içinde tanımlı P iç hücre verilsin. P iç hücresi tam alt ağ olduğu gibi tek nokta da olabilmektedir. Her $x \in V\left(K_{n: n \geq 3}\right)$ için bu noktanın ağırlı̆̆ $\lambda(x)$ şeklinde gösterilsin. $K_{n: n \geq 3}$ tam yapılı ağ içinde 
tanımlı tek P iç hücre varlığı için aşağıda verilecek olan işlem süreci yardımı ile optimal değeri sağlayan $x \in V\left(K_{n: n \geq 3}\right)$ noktası hesaplanır. (Zhang vd., 2010: 105)

$$
\begin{aligned}
& f_{K_{n n \geq 3}}(x)=\sum_{i=1}^{n} \lambda\left(x_{i}\right) d\left(x_{i}, x\right)+\lambda(\mathrm{P}) d(\mathrm{P}, x) \\
& f_{K_{n n \geq 3}}^{*}=\min _{x_{i} \in V\left(G_{x}\right)} f_{K_{n n \geq 3}}\left(x_{i}\right) \\
& f_{K_{n n \geq 3}}\left(x_{i}\right)=\left\{\begin{array}{l}
\sum_{i=1}^{n} \lambda\left(x_{i}\right)-\lambda\left(x_{i}\right): x_{i} \in V(\mathrm{P}) \\
\sum_{i=1}^{n} \lambda\left(x_{i}\right)+\lambda(\mathrm{P})-\lambda\left(x_{i}\right)
\end{array}\right.
\end{aligned}
$$$$
x \in V(\mathrm{P}) \text { ve } y \in V\left(K_{n: n \geq 3}\right) \quad V(\mathrm{P}) \text { noktaları için }
$$

(14) numaralı denkleme ait elde edilen sonuçlardan hareketle optimumu sağlayan $x \in V\left(K_{n: n \geq 3}\right)$ noktası elde edilir.

\section{III.d Blok Ağlar Üzerinde Optimizasyon}

$G=(N, E, \lambda, \mu)$ blok ağ yapısı özelliğine sahip, her ă içinde tanımlı iç hücrenin tam olduğu ve $\Omega=\left(N_{\Omega}, E_{\Omega}\right)$ indirgenmiş ağaç yapısına sahip özel durum verilsin. Önceki iki alt bölüm yardımı ile (1) numaralı denklemi sağlayan $x \in V(G)$ elemanı aşağıdaki şekilde elde edilir. Öncelikle $G=(N, E, \lambda, \mu)$ içindeki iç hücrelere yakınlık temel alındığından her $\quad x \in V(G)$ için $\quad \lambda(x)=0 \quad$ alırız. $\Gamma_{N}=\sum_{\mathrm{P}_{i} \subseteq G} \lambda\left(\mathrm{P}_{i}\right)$ değeri, ağ içindeki iç hücre ağırlıklarını göstersin. (Zhang vd., 2010: 109)

$$
\begin{aligned}
& \lambda_{L}^{*}(x)=\sum_{\mathrm{p}_{i} \in N\left[S_{x}\right]} \lambda\left(\mathrm{p}_{i}\right) \\
& \lambda_{X}^{*}(x)=\Gamma_{N}-\sum_{\mathrm{p}_{i} \in N\left[S_{x}\right]} \lambda\left(\mathrm{P}_{i}\right)
\end{aligned}
$$

$A$ blok yapısından önce gelen $H$ noktası için

\section{Sonuç}

Organize suç ve terör örgütlerinin üyelerinin niteliksel özellikleri, organizasyonlar içindeki hiyerarşik yapının varlı̆g 1 gibi üyeler arasında mukayese edilebilecek kriterlerin ağ analizine eklenmesi, organizasyonların iskeletinin daha gerçekçi şekilde ortaya çıkarılması için oldukça önemlidir. Klasik merkezi analiz metotları organizasyon üyelerinin homojen olduğu varsayımından hareket etmesi elde edilen sonucun güvenilirliğinin sorgulanmasına sebep olmaktadır. Organizasyon içinde tanımlayabileceğimiz değişkenler üyelere atanan sayısal değerler olduğu gibi (örn: eylem deneyiminin 1-5 arasında bir tam sayı ile ifadesi), üyeleri birbirine doğrudan bağlayan doğru parçasına ( örn: iki üye arasındaki samimiyet derecesi) atanan değerlerde olabilir. Bu sayede örneğin bir organize suç veya terör örgütü içinde belli hücrelerden istihbarat elde edebilecek kilit üye, ilgili üyeler ile samimiyet ilişkisi ve gelen bilginin güvenilirliği kısıtlarına göre bulunacaktır. Blok yapılı ve hücre yapıları tam olan ağlar için ilgili çözüm süreci gösterilmiştir.

$$
\tilde{\lambda}(H)=\Gamma_{N}-\sum_{\mathrm{p}_{i} \in N\left[S_{A}\right]} \lambda\left(\mathrm{P}_{i}\right)
$$

İlgili $H \in V\left(N_{\Omega}\right)$ noktası birden fazla blok yapısını bağliyorsa

$$
\tilde{\lambda}\left(H_{j}\right)=\sum_{\mathrm{p}_{i} \in N\left[S_{H_{j}}\right]} \lambda\left(\mathrm{P}_{i}\right)
$$

III.b ve III.c 'de tanımlanan süreçlerden hareketle $f_{A}^{*}, \beta_{A}$, $f_{A}(H)$ ve $f_{A}\left(H_{j}\right)$ değerleri hesaplansın. $H_{j}$ noktasından ile doğrudan bağlantılı olup bu noktadan sonra gelen $B_{j_{l}} \in V\left(N_{\Omega}\right)$ blokları için

$\Delta\left(A, B_{j_{l}}\right)=f\left(\beta_{A}\right)-f\left(B_{j_{l}}\right)$

$\Delta^{*}(A)=\left\{\begin{array}{l}0: A \in V\left(N_{\Omega}\right) \text { ağaç için son eleman kümesinde ise } \\ \max _{j, l}\left\{0, \Delta\left(A, B_{j_{l}}\right)+\Delta^{*}\left(B_{j_{l}}\right)\right\}\end{array}\right.$

$$
\begin{aligned}
& \alpha(A)=\left\{\begin{array}{l}
\beta_{A}: \Delta^{*}(A)=0 \\
\beta\left(B^{*}\right): \Delta^{*}(A)=\Delta\left(A, B^{*}\right)+\Delta^{*}\left(B^{*}\right)
\end{array}\right. \\
& \Phi(A)=\left\{\begin{array}{l}
f_{A}(H): A \in V\left(N_{\Omega}\right) \text { ağaç için son eleman kümesinde ise } \\
f_{A}+\sum_{i, l} \Phi\left(B_{j_{l}}\right): A \in V\left(N_{\Omega}\right) \text { ağaç için başlangiç noktası ise } \\
f_{A}(H)+\sum_{i, l} \Phi\left(B_{j_{l}}\right)
\end{array}\right.
\end{aligned}
$$

Yukarıdaki süreç sonuncunda elde edilen değerleri için aşağıdaki işlem optimal değeri, bu değeri sağlayan nokta ise optimalliği sağlayan noktayı verir.

$$
f^{*}=\Phi-\Delta^{*}
$$

\section{Kaynakça}

Ballester, C. -Calvo-Armengol, A. -Zenou, Y. (2006), "Who's Who İn Networks. Wanted: The Key Player", Econometrica, Cilt: 74, Say1: 5, S: 1403-1417

Bukard, R. E. -Krarup, J. (1998), “A Linear Algorithm Fort $\mathrm{He}$ Pos/Neg-Weighted 1-Median Problem On A Cactus", Computing, Sayı: 60, S: 193-215

Cheng, Y. -Kang, L. -Lu, C. (2010), "The Pos/NegWeighted 1-Median Problem On Tree Graphs With Subtree-Shaped Customers", Theoretical Computer Science, S: 1038-1044

Krebs, V. (2002), "Unlocking Terrorist Networks", First Monday, cilt:7, say1:4, http://journals.uic.edu/ojs/index.php/fm/article/view/ $\underline{941}(15.10 .2013)$

Puerto, J. - Tamır, A. -Mesa, J. A. - Perez-Brito, D. (2008), "Center Location Problems On Tree Graphs With Subtree-Shaped Customers", Sayı: 156, S: 2890-2910 
Zhang, X. -Kang, L. -Cheng Y. (2010), “The Pos/NegWeighted Median Problem On Block Graphs With Subgraph-Shaped Customers", Computing, Say1:88, S: 97110

Zmazek, B. -Zerovnık, J. (2004), "The Obnoxious Center Problem on Weighted Cactus Graphs", Discrete Applied Mathematics, say1: 136, s: 377-386 